Research Article

www.jestr.org

\title{
Numerical Analyses on Seismic Behaviour of Concrete-filled Steel Tube Composite Columns Based on OpenSEES Program
}

\author{
Hong-zhen KANG ${ }^{1, *}$, Xi-min SONG ${ }^{2}$, Kai-wu JIA ${ }^{3}$, Li-ping ZHOU $^{4}$ and Ping LIU ${ }^{5}$ \\ ${ }^{1,2,3}$ Department of Civil Engineering, Tangshan College, Tangshan 063000-China \\ ${ }^{4}$ Institute of building design and research of Tangshan, Tangshan 063000-China \\ ${ }^{5}$ School of Building Engineering, Hebei United University, Tangshan 063009-China
}

Received 28 June 2013; Accepted 16 December 2013

\begin{abstract}
In order to study seismic behaviour of concrete-filled steel tube composite columns under low-cyclic load, using finite element software OpenSEES, numerical simulation is carried out in this paper. The results indicate that OpenSEES can simulate well hysteretic curves and skeleton curves of concrete-filled steel tube composite columns under low-cyclic load, and the simulated peak load showed good agreement with the test results, with errors no more than $10 \%$. The simulative hysteretic curve shapes are nearly similar to that of test results, and can describe degradation of their stiffness and strength in the cyclic loading process.
\end{abstract}

Keywords: Steel Tube-reinforced Concrete Composite Column, Fiber Model; Seismic Behaviour, OpenSEES, Numerical Analysis

\section{Introduction}

The steel tube-reinforced concrete (ST-RC) composite column is a novel type of composite column, which consists of a steel tube embedded in RC. Recently, this type of composite column has seen increasing use in China. Up until now, more than 40 high-rise buildings that use the ST-RC composite columns have been constructed in earthquakeprone regions, with the tallest among them over $280 \mathrm{~m}$ tall. In the past decade, many efforts have been made to study the performance of ST-RC composite members, for example, Kang and Qian [1-3] and Han et al. [4]. With the results of study efforts, the CECS188:2005 (Technical specification for steel tube-reinforced concrete column structure)[5] has been established in China to guide the design of this type structures.

Numerical analyses of finite element methods on ST-RC composite column performance can extend the experimental data of this type of columns. In this paper, based on OpenSEES program, the hysteretic analysis fiber element model has been proposed to analyze seismic behaviour of 4 experimental ST-RC composite columns. The simulation results show better agrees with the experimental data.

\section{Fiber models and element models}

\subsection{Fiber models and element models}

The OpenSEES program offers several section restoring force models including elastic restoring force model, ideal elastic and plastic restoring force model, 2 straight-line

\footnotetext{
*E-mail address: thkhz@sina.com

ISSN: 1791-2377@ 2013 Kavala Institute of Technology. All rights reserved.
}

strengthened restoring force model and hysteretic restoring force model, it also offers a refined fiber model which is used in this paper. The main approach of the fiber model is that the member section is divided into some small fiber unit while the shear strain of the fiber unit and the bonding slippage of the steel bars are neglected. The basic assumptions are the section deformation is plane and the strain of each fiber unit on the section is uniaxial stress and strain state and uniform distribution. Thus, forcedeformation relationship of the whole section can be calculated through the uniaxial stress-strain relation of each fiber unit.

\subsection{Member element model}

The OpenSEES program offers several elements for members which mainly include two types of solid elements and beam-column elements. The solid elements consist of two-dimension and three-dimension finite unit solid elements while beam-column models consist of truss element, elastic beam element, nonlinear beam column element and zero dimension element. Nonlinear beam column element is used in these analyses, the characteristic of which is that the element is interpolation function beamcolumn element, its longitudinal stiffness is various, longitudinal integration control sections are multiple.

\section{Materials constitutive relation}

\subsection{Concrete constitutive model} 3.1.1 Plain concrete

The covering layer of the ST-RC composite columns is plain concrete, hence it employs Scott-Kent-Park model [6] which 
is popular for many researchers to adopt. This model can be described as following equations:

$\sigma_{c}=\left\{\begin{array}{lc}f_{c}^{\prime}\left[\frac{2 \varepsilon_{c}}{\varepsilon_{0}}-\left(\frac{2 \varepsilon_{c}}{\varepsilon_{0}}\right)^{2}\right] & \left(\varepsilon_{c}<\varepsilon_{0}\right) \\ f_{c}^{\prime}\left[1-Z_{m}\left(\varepsilon_{c}-\varepsilon_{0}\right)\right. & \left(\varepsilon_{0}<\varepsilon_{c}<\varepsilon_{20}\right) \\ 0.2 f_{c}^{\prime} & \left(\varepsilon_{c}>\varepsilon_{20}\right)\end{array}\right.$

Where, $\sigma_{c}$ is the concrete stress, $\varepsilon_{c}$ is the concrete stain, $f_{c}^{\prime}$ is the concrete compressive strength (MPa), $\varepsilon_{0}$ is the concrete peak strain, $\varepsilon_{20}$ is concrete strain with the stress decreasing at $20 \%$ peak stress, and $Z_{\mathrm{m}}$ is the slope of decreasing stage. Hence:

$$
\varepsilon_{0}=0.002
$$

$$
Z_{m}=\frac{0.5}{\frac{3+0.29 f_{c}^{\prime}}{145 f_{c}^{\prime}}-0.002}
$$

\subsubsection{Confined concrete out of steel tube}

The stress-strain relation of confined concrete out of steel tube adopts the Saaticioglu Model [7] as indicated in Fig. 1. This model consists of a parabolic ascent curve and a descent straight line.

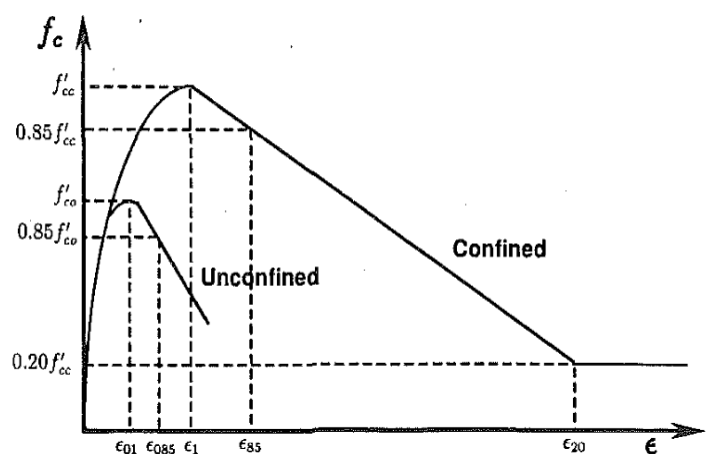

Fig. 1 Stress-strain relationship of plain and confined concrete

$$
f_{c}=f_{c c}^{\prime}\left[2\left(\frac{\varepsilon_{c}}{\varepsilon_{1}}\right)-\left(\frac{\varepsilon_{c}}{\varepsilon_{1}}\right)^{2}\right]^{1 /(1+2 K)} \leq f_{c c}^{\prime}
$$

Where: $f_{c}, \varepsilon_{c}$ are stress and strain of confined concrete respectively, $f_{c c}^{\prime}, \varepsilon_{1}$ are the peak stress and peak strain of confined concrete respectively, $K$ is the ratio of peek stress of confined concrete to peek stress of plain concrete.

$$
f_{c c}^{\prime}=f_{c 0}^{\prime}+k_{1} f_{l e}
$$

where:

$$
f_{l e}=k_{2} f_{l}
$$

$$
f_{l}=\frac{\sum A_{s} f_{y t} \sin \alpha}{s b_{c}}
$$

$k_{1}=6.7\left(f_{l e}\right)^{-0.17}$

where $A_{\mathrm{s}}$ is section area of one stirrup, $f_{y t}$ is the yield strength of stirrup, $s$ is the spacing of stirrups, $b_{c}$ is the length of core concrete area, $\alpha$ is the angle between stirrup and section side length, $f_{l}$ is mean lateral confined stress, $f_{l e}$ is the equivalent lateral confined stress, $k_{1}$ is the increase coefficient to axial compressive strength by lateral confined stress, and $k_{2}$ is calculated by:

$k_{2}=0.26 \sqrt{\left(\frac{b_{c}}{s}\right)\left(\frac{b_{c}}{s_{1}}\right)\left(\frac{1}{f_{l}}\right)} \leq 1.0$

$\varepsilon_{1}=\varepsilon_{01}(1+5 K)$

$k=\frac{k_{1} f_{l e}}{f_{c o}^{\prime}}$

Where $\varepsilon_{01}$ is about 0.002 . Concrete strain with stress decreasing at $85 \%$ peak stress is $\varepsilon_{85}$, which is computed as :

$\varepsilon_{85}=260 \rho \varepsilon_{1}+\varepsilon_{085}$

$\rho=\frac{\sum A_{s}}{s\left(b_{c x}+b_{c y}\right)}$

While the loading is at slower speed, $\varepsilon_{85}$ is 0.0038 . $\sum A_{s}$ is the total section area of two direction stirrups.

\subsubsection{Confined concrete in steel tube}

The stress-strain relation of concrete confined by steel tube adopts Susantha Model [8], in which, the stress-strain relationship before peak stress uses the Mander Model [9]. Then, the stress-strain curve is showed in Fig. 2.

The ultimate strain of confined concrete is defined as 0.0025 , so the peak stress is computed as following equations:

$f_{c c}^{\prime}=f_{c}^{\prime}+4.0 f_{r p} f_{c c}^{\prime}=f_{c}^{\prime}+4.0 f_{r p}$ 
$f_{r p}=\beta \frac{2 t}{D-2 t} f_{y} f_{r p}=\beta \frac{2 t}{D-2 t} f_{y}$

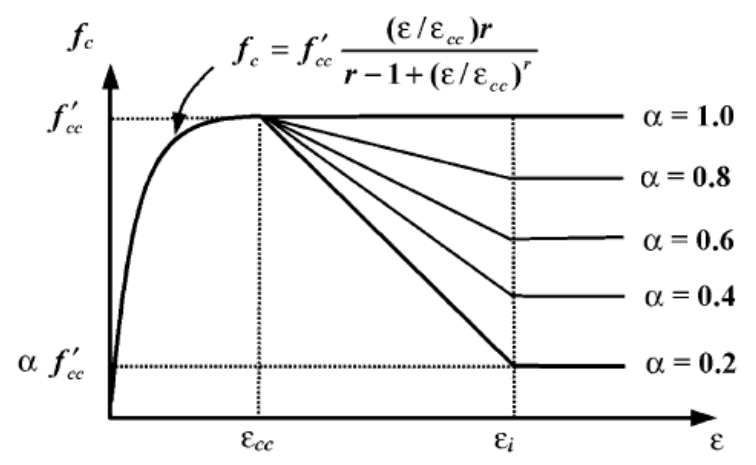

Fig. 2 Stress-strain relationship of Susantha Model

Where $f_{c}^{\prime}$ is the peak strain of plain concrete, $f_{c c}^{\prime}$ is the peak strain of confined concrete, $\mathrm{D}$ is the diameter fo steel tube, $t$ is the steel tube thickness, $f_{y}$ is the field strength of steel tube,and $\beta$ is the ratio of steel tube circumferential stress to field strength, which is computed as:

$$
\beta=v_{e}-v_{s}
$$

Where $v_{e}$ and $v_{s}$ are the Poisson's ratios of concreteconfined steel tube and steel tube only respectively.

$$
\begin{aligned}
& v_{e}=0.2312+0.3582 v_{e}^{\prime}-0.1524\left[\frac{f_{c}^{\prime}}{f_{y}}\right]+4.843 v_{e}^{\prime}\left[\frac{f_{c}^{\prime}}{f_{y}}\right]-9.169\left[\frac{f_{c}^{\prime}}{f_{y}}\right]^{2} \\
& v_{e}^{\prime}=0.881 \times 10^{-6}\left(\frac{D}{t}\right)^{3}-2.58 \times 10^{-4}\left(\frac{D}{t}\right)^{2}+1.953 \times 10^{-2}\left(\frac{D}{t}\right)+0.401
\end{aligned}
$$

The slope of descent stage $Z$ is calculated as:

$$
Z= \begin{cases}0 & R_{t} \frac{f_{c}^{\prime}}{f_{y}} \leq 0.006 \\ 1.0 \times 10^{5} R_{t} \frac{f_{c}^{\prime}}{f_{y}}-600 & R_{t} \frac{f_{c}^{\prime}}{f_{y}} \geq 0.006 \text { and } f_{y} \leq 283 \mathrm{MPa} \\ 1.0 \times 10^{6} R_{t} \frac{f_{c}^{\prime}}{f_{y}}-6000 & R_{t} \frac{f_{c}^{\prime}}{f_{y}} \geq 0.006 \text { and } f_{y} \geq 336 \mathrm{MPa} \\ \left(\frac{f_{y}}{283}\right)^{134}\left[1.0 \times 10^{5} R_{t} \frac{f_{c}^{\prime}}{f_{y}}-600\right] & R_{t} \frac{f_{c}^{\prime}}{f_{y}} \geq 0.006 \text { and }^{\prime} 283 \mathrm{MPa} \leq f_{y} \leq 336 \mathrm{MPa}\end{cases}
$$

$R_{t}=\sqrt{3\left(1-v^{2}\right)} \frac{f_{y}}{E_{s}} \frac{D}{2 t}$

Where $v$ is Poisson's ratio of steel tube in elastic state. $E_{\mathrm{s}}$ is the elastic modulus of steel tube, and $R_{\mathrm{t}}$ is factor related with tube thickness.

\section{2 Steel constitutive model}

In this study the stress-strain relationship of steel tube and reinforced steel bar employs Giuffre-Menegotto-Pinto Model [10], which is illustrated as Fig. 3 and expressed by Equation (21), (22), (23) and (24).

$$
\sigma^{*}=b \varepsilon^{*}+\frac{(1-b) \varepsilon^{*}}{\left(1+\varepsilon^{* R}\right)^{1 / R}}
$$

$$
\begin{aligned}
& \sigma^{*}=\frac{\sigma-\sigma_{r}}{\sigma_{0}-\sigma_{r}} \\
& \varepsilon^{*}=\frac{\varepsilon-\varepsilon_{r}}{\varepsilon_{0}-\varepsilon_{r}} \\
& R=R_{0}-\frac{\alpha_{1 \xi}}{\alpha_{2}+\xi}
\end{aligned}
$$

Where $R, \xi$ are relative factors, $R_{0}$ is the initial value of $R$, all of $a_{1}, a_{2}$ and $R_{0}$ are measured by test material results.

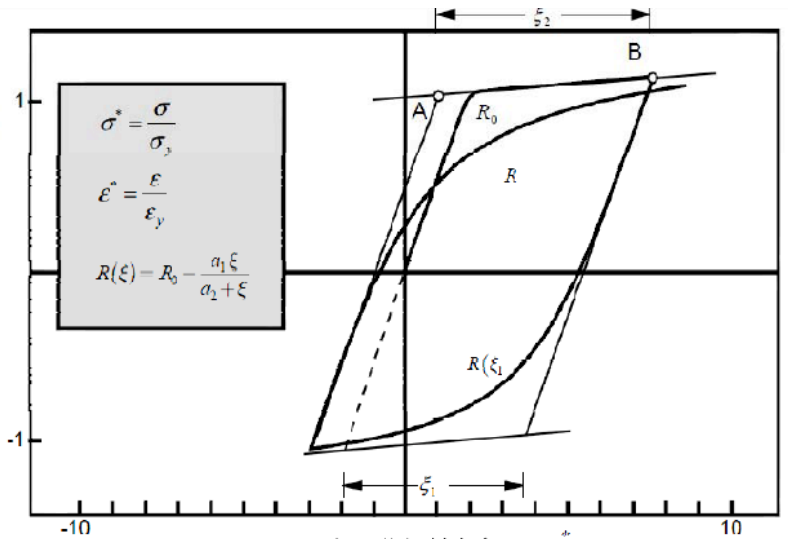

Fig. 3 Steel stress-strain relationship of Giuffre-Menegotto-Pinto Model

\section{Element division of cross sections and columns}

For better comparison of calculation with test results, the calculation employs the specimens CCS1, CCS2, CCS3, CCS4 and CCS5 of the literature [11] as the cases. Their sections are divided as showing in Fig. 4.

As indicated in Fig. 4, each fiber unit dimension is $15 \mathrm{~mm} \times 15 \mathrm{~mm}$.

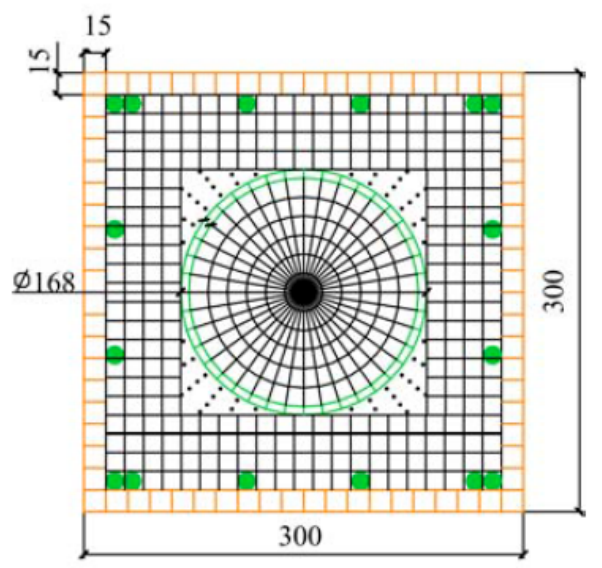

Fig. 4 Section division of calculation specimens 
The column models are adopted as displacement-based beam-column element, which are indicated in Fig. 5. Along the longitudinal direction of the column, under the lateral loading point it is divided five finite elements while upper the loading point one finite element is distributed. In each element 3 integration point are defined for calculation. The column element is showed in Fig. 5.

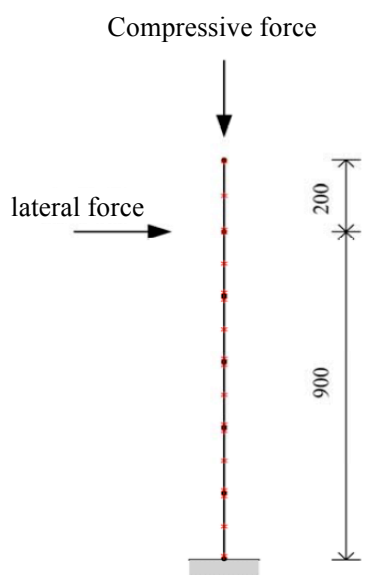

Fig. 5 Column element division

\section{Analyses of calculation results}

\section{1 Skeleton curve simulation results analyses}

Based on OpenSEES program, the lateral force-displacement skeleton curves of specimens CCS1, CCS2, CCS3, CCS4 and CCS5 of the literature [11] are calculated. The numerical simulation results are showed in Fig. 6.

In Fig. 6, the dotted lines express the numerical simulating results while the solid lines indicate the experimental results.

By comparison of dotted lines with solid lines, the simulating curves are basically agreed with the experimental curves. This indicates that OpenSEES program is suitable to analyze the seismic behavior of ST-RC composite columns. Yet, some errors are existed.

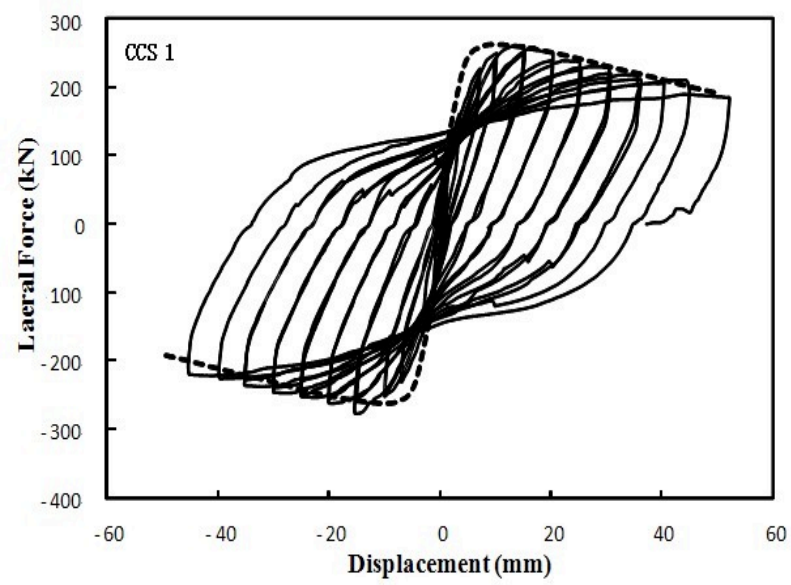

(a) Numerical simulation result of CCS1

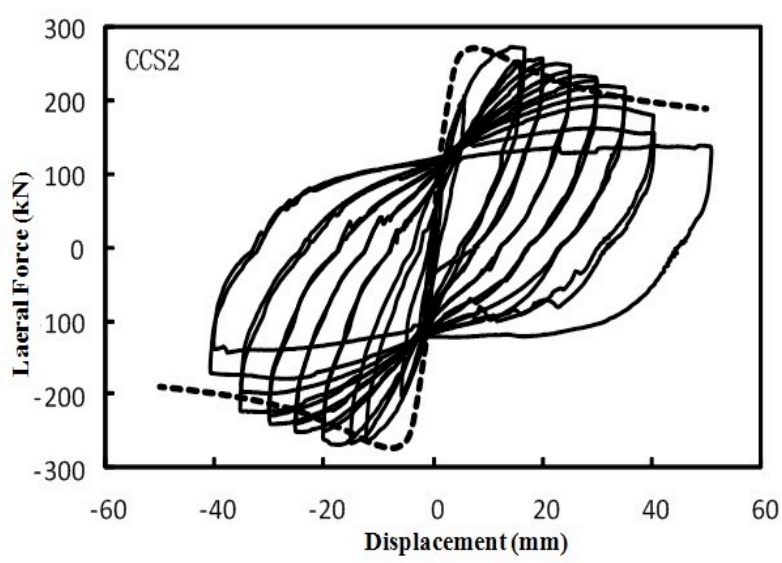

(b) Numerical simulation result of CCS2

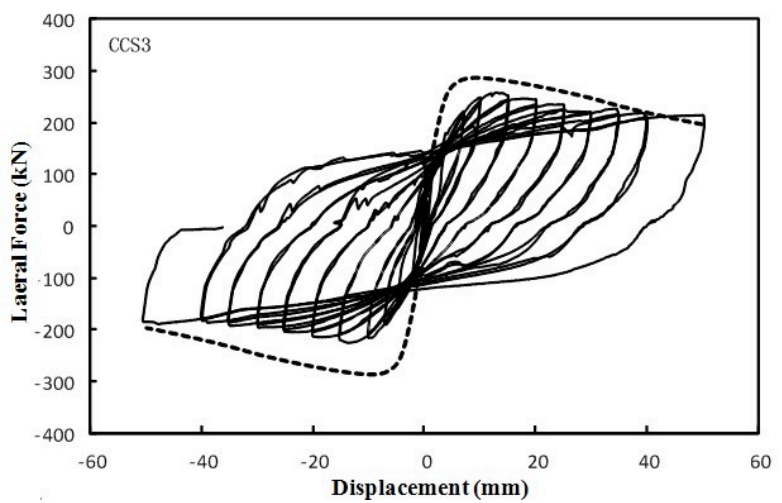

(c) Numerical simulation result of CCS3

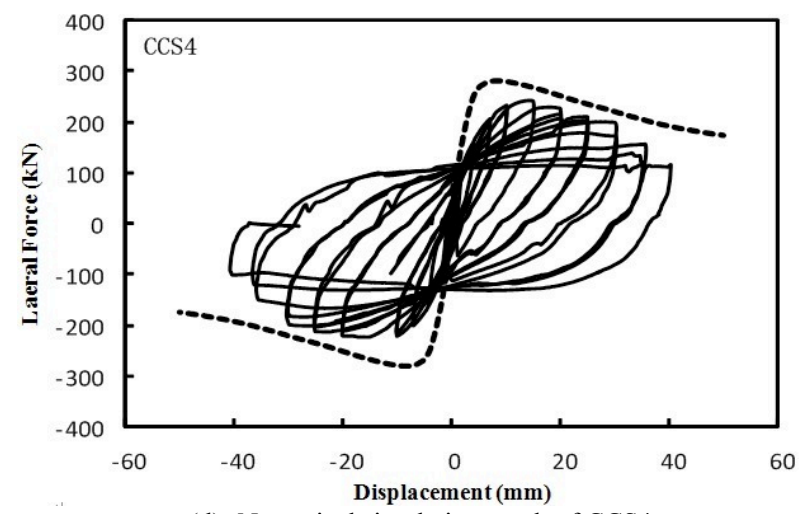

(d) Numerical simulation result of CCS4

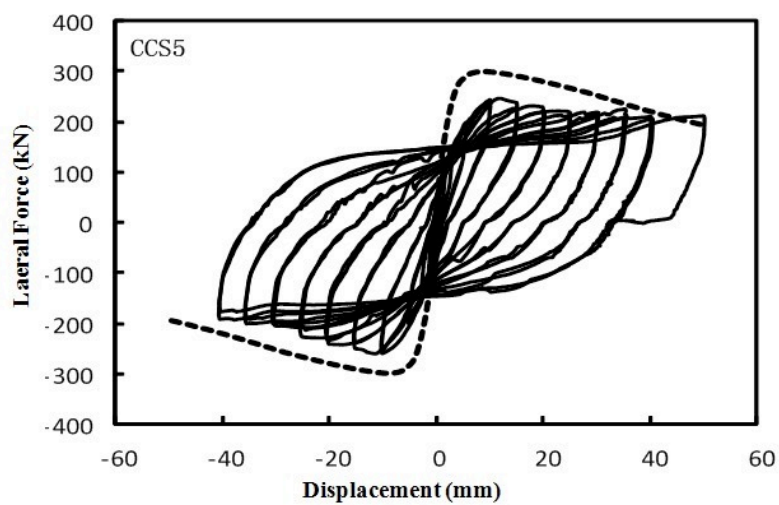

(e) Numerical simulation result of CCS5

Fig. 6 Numerical simulation results of skeleton curves 
In the aspect of peak lateral bearing capacity, the numerical results are some greater than that of experimental results. On the one hand, in the initial loading period, single stirrup should not apply confinement for concrete because of construction error. On the other hand, since the concrete dimension out of the steel tube is smaller comparing with the stirrup spacing, the confinement action supplied by circle stirrups is smaller than that of the simulating model. As a result, it should be proposed that the single stirrup confinement action be not taken in consideration when the concrete peak stress and strain are calculated, while, when the ultimate stress and strain are calculated its confinement be taken into account.

In the aspect of stiffness, the numerical calculating results are obviously greater than that of experimental results, which should be attributed to two reasons. The first is that the specimen column bottom is not as stiff as ideal solid joint in finite model. The second is that the bonding slippage between steel tube and outer concrete are not taken into account in the calculation model[12].

\section{2 Hysteresis loop simulation results analyses}

Based on OpenSEES program, the lateral force-displacement hysteresis loops of specimens CCS1, CCS2, CCS3, CCS4 and CCS5 of the literature [11] are calculated. The numerical simulation results are showed in Fig. 7.

In Fig. 7 the dotted lines express the numerical simulating results while the solid lines indicate the experimental results.

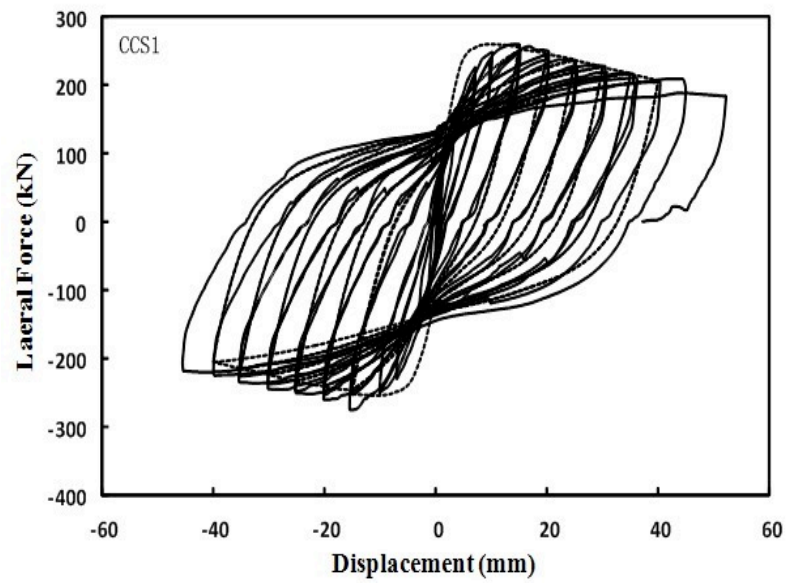

(a) Numerical simulation result of CCS1

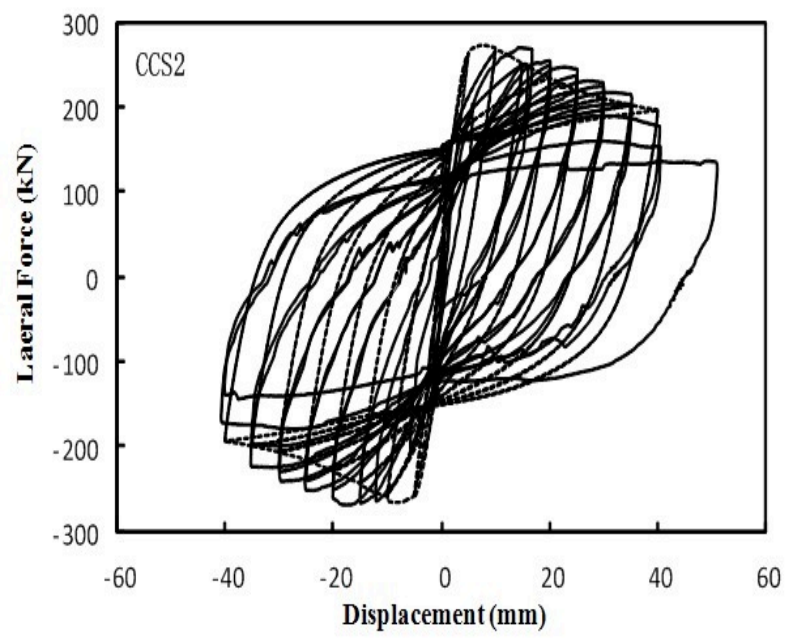

(b) Numerical simulation result of CCS2

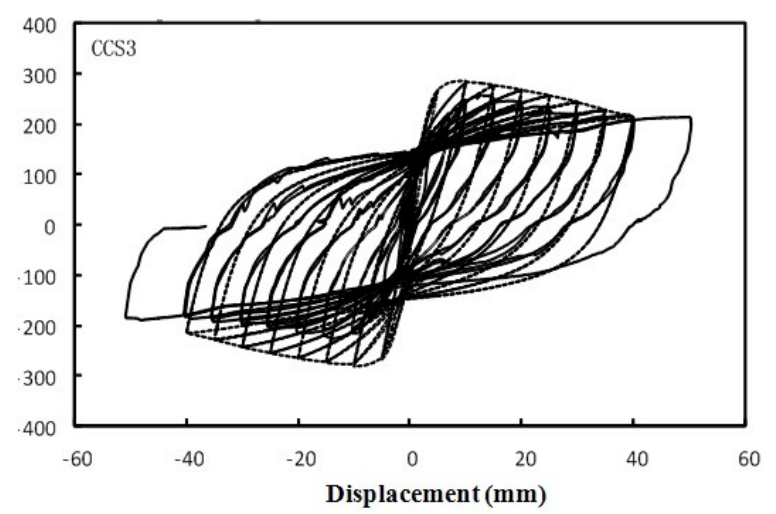

(c) Numerical simulation result of CCS3

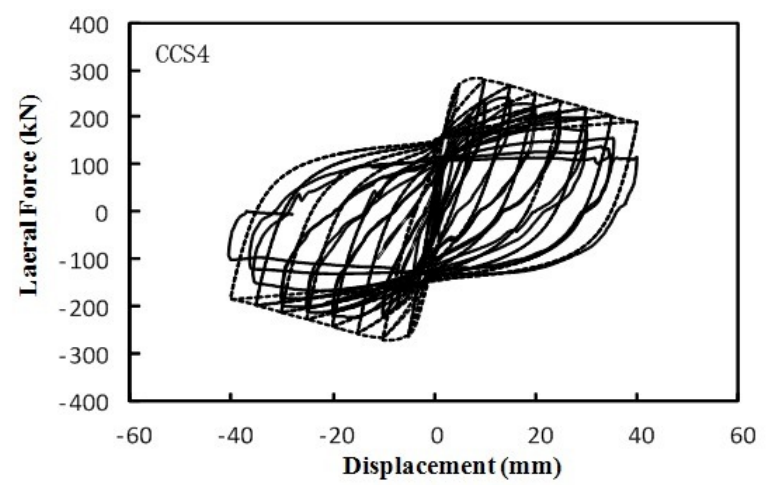

(d) Numerical simulation result of CCS4

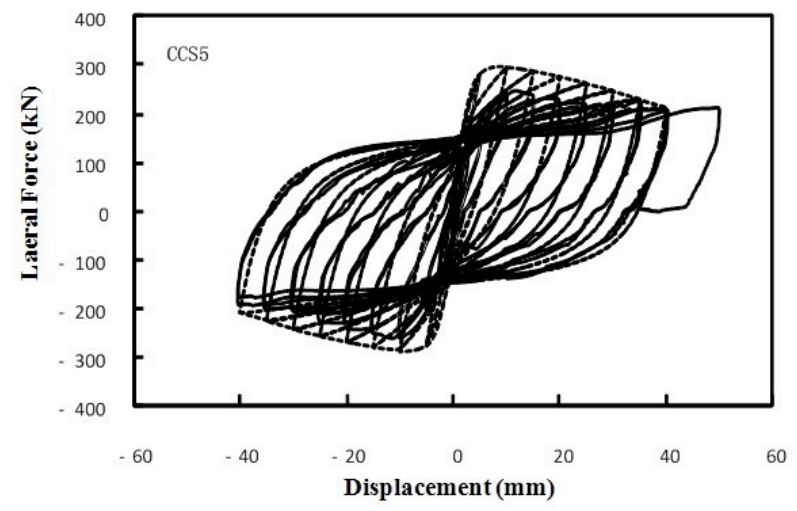

(e) Numerical simulation result of CCS5

Fig. 7 Numerical simulation results of hysteresis loops

Considering of the reducing confinement of the single stirrup, the stress-strain model of confined concrete used in the part is modified, that is, before the peak stress the single stirrup confinement is neglected. By comparison the calculation results and the experimental results, the numerical simulation hysteresis loops of ST-RC composite columns based on OpenSEES is feasible.

\section{Conclusions}

Based on OpSEES program, the seismic behavior, such as the skeleton curves and hysteresis loops, of ST-RC composite columns are simulated numerically. The analyses indicated that the simulating results are better agreed with that of experimental results. The fiber element of OpenSEES is suitable to simulate seismic behavior of composite columns. On the other hand, because of employment of uniform cross section assumption in the fiber model of OpenSEES program, the bonding slippage between steel 
tube and concrete along with reinforcement bars and concrete is not be taken into account, the gap between simulation results and experimental results should be covered further in the subsequent study.

\section{Acknowledgements}

This work was sponsored by the Construction Technology Innovation Program of Hebei Province of China (2011-106).

\section{References}

1. Kang H, Qian J. "Experimental study on high-strength concrete filled steel tube composite columns under axial compressive loading”. Proceedings of the Tenth East Asia - Pacific Conference on Structural Engineering and Construction. Bangkok, 2006, pp. 69 -74 .

2. Qian J, Kang H. "Experimental study on seismic behavior of highstrength concrete-filled steel tube composite columns", Journal of Building Structures, 30(4), 2009, pp. 85-93 (in Chinese).

3. Qian J, Jiang Z, Ji X. "Behavior of steel tube-reinforced concrete composite walls subjected to high axial force ratio and cyclic loading". Engineering Structures, 36(3), 2012, pp.173-184.

4. Han LH, Liao FY, Tao Z, Hong Z. "Performance of concrete filled steel tube reinforced concrete columns subjected to cyclic bending", Journal of Constructional Steel Research, 65(8-9), 2009, pp. 16071616.

5. CECS188:2005."Technical specification for steel tube-reinforced concrete column structure", China Planning Press, Beijing, 2005.

6. Scott B D, Park R, Priestley M J N. "Stress-strain behavior of concrete confined by overlapping hoops at low and high strain rates”, ACI Journal, 79( 2), 1982, pp. 13-27.
7. Razvil Salim, Saatcioglu Murat, "Confinement model for highstrength concrete", Journal of Structural Engineering, ASCE, 125( 3), 1999, pp.281-289.

8. Susantha K A S, Ge Hanbin, Usami Tsutomu, "Uniaxial stress strain relationship of concrete confined by various shaped steel tubes”, Engineering Structures, 23, 2001, pp. 1331-1347.

9. Mander J B, Priestley M J N, Park R, "Theoretical stress-strain model for confined concrete", Journal of Structural Engineering, ASCE, 114(8), 1988, pp. 1804-1826.

10. Menegotto M, Pinto P E, "Method of analysis for cyclically loaded reinforced concrete plane frames including changes in geometry and non-elastic behavior of elements under combined normal force and bending", IABSE symposium on resistance and ultimate deformability of structural acted on by well-defined repeated loads , Lisbon, 1973, pp.15-22.

11. Kang H., "Study on Mechanical Properties of Concrete-filled Steel Tube Composite Columns", Tsinghua University, 2009.

12. B. S. Reddy, N. J. Krishna, J.S. Kumar and K.V.K. Reddy, "Prediction of Surgace Roughness in End Milling of P20 MouldSteel Using Artificial Neural Networks", Journal of Engineering Science And Technology Review. 2012, 5(1),pp.7-13. 